\title{
A cellular, molecular, and pharmacological basis for appendage regeneration in mice
}

\author{
Thomas H. Leung, ${ }^{1,2,5}$ Emily R. Snyder, ${ }^{1}$ Yinghua Liu, ${ }^{1}$ Jing Wang, ${ }^{1}$ and Seung K. Kim ${ }^{1,3,4}$ \\ ${ }^{1}$ Department of Developmental Biology, Stanford University School of Medicine, Stanford, California 94305, USA; \\ ${ }^{2}$ Department of Dermatology, Stanford University School of Medicine, Stanford, California 94305, USA; ${ }^{3}$ Howard Hughes \\ Medical Institute, Stanford University School of Medicine, Stanford, California 94305, USA; ${ }^{4}$ Department of Medicine, \\ Oncology Division, Stanford University School of Medicine, Stanford, California 94305, USA
}

Regenerative medicine aims to restore normal tissue architecture and function. However, the basis of tissue regeneration in mammalian solid organs remains undefined. Remarkably, mice lacking p21 fully regenerate injured ears without discernable scarring. Here we show that, in wild-type mice following tissue injury, stromal-derived factor-1 (Sdf1) is up-regulated in the wound epidermis and recruits Cxcr4-expressing leukocytes to the injury site. In p21-deficient mice, Sdf1 up-regulation and the subsequent recruitment of Cxcr4-expressing leukocytes are significantly diminished, thereby permitting scarless appendage regeneration. Lineage tracing demonstrates that this regeneration derives from fate-restricted progenitor cells. Pharmacological or genetic disruption of Sdf1-Cxcr4 signaling enhances tissue repair, including full reconstitution of tissue architecture and all cell types. Our findings identify signaling and cellular mechanisms underlying appendage regeneration in mice and suggest new therapeutic approaches for regenerative medicine.

[Keywords: developmental biology; genetics; molecular biology; regenerative medicine; tissue regeneration]

Supplemental material is available for this article.

Received June 19, 2015; revised version accepted September 25, 2015.

In mammals, traumatic injuries typically heal with a fibroblast- and collagen-rich response, producing a fibrous scar rather than full reconstitution of cellular subtypes and functional tissue architecture. A central focus of regenerative and developmental biology is to restore normal tissue structure and function after injury. Astonishing examples of tissue and organ regeneration following injury include appendage and eye regeneration in amphibians and teleosts (Carlson 2007). Limited examples of tissue regeneration also exist in mammals, suggesting that mechanisms governing tissue regeneration may be evolutionarily conserved. Here, we investigated mouse ear regeneration to identify cellular, genetic, and signaling mechanisms driving mammalian appendage regeneration.

Murphy-Roths-Large (MRL) mice and genetically related strains demonstrate enhanced tissue regeneration after injury to ears, cornea, digit tips, and the heart (Ueno et al. 2005; Chadwick et al. 2007; Edwards 2008). Histological analysis of MRL ear hole closure is reminiscent of ear regeneration observed in rabbits, cats, and other mammals. Improved ear regeneration has also been reported in mice lacking p21 (also known as Cdkn1a, Cip1, and Waf1). Similar to MRL mice, the molecular or cellular basis of ear re-

\footnotetext{
${ }^{5}$ Present address: Department of Dermatology, University of Pennsylvania, Philadelphia, PA 19104, USA.

Corresponding authors: seungkim@stanford.edu, thl@upenn.edu

Article is online at http://www.genesdev.org/cgi/doi/10.1101/gad.267724.

115 .
}

generation in $\mathrm{p} 21^{-/-}$mice has not been defined (Bedelbaeva et al. 2010). p21 protein is an established cyclin-dependent kinase (CDK) inhibitor and regulator of the cell cycle. Disruption of the cell cycle may explain the increased rate of ear hole closure, but mice lacking other cell cycle checkpoint regulators such as p53, p16, and Gadd45 did not improve ear hole regeneration (Arthur et al. 2010). Thus, we postulated that p21 cell cycle-independent functions may affect tissue regeneration. For example, p21 has been linked to the regulation of transcription, aging, cellular senescence, and cell reprogramming (Kippin 2005; Choudhury et al. 2007).

From prior quantitative trait locus (QTL) mapping studies in MRL mice (Cheverud et al. 2012), we identified one locus linked to regenerative capacity that contained the gene for stromal cell-derived factor-1 (Sdf1; also known as Cxc112). Sdf1 binds to the chemokine receptor Cxcr4, and increased Sdf1-Cxcr4 signaling has been linked to increased fibrosis and scar formation in multiple tissues, including the lung, liver, and heart. In zebrafish fin regeneration, overexpression of Sdf1 abrogated tissue regeneration (Dufourcq and Vriz 2006). In contrast, Cxcr4 loss-of-

(C) 2015 Leung et al. This article is distributed exclusively by Cold Spring Harbor Laboratory Press for the first six months after the full-issue publication date (see http://genesdev.cshlp.org/site/misc/terms.xhtml). After six months, it is available under a Creative Commons License (Attribution-NonCommercial 4.0 International), as described at http:// creativecommons.org/licenses/by-nc/4.0/. 
function mutations promoted hepatocyte regeneration in a liver injury model (Ding et al. 2014), and pharmacologic inhibition of Cxcr4 prevented lung fibrosis in a radiationor bleomycin-induced injury model (Makino et al. 2013; Shu et al. 2013). Together, these results indicate that Sdf1 and Cxcr4 may play a role in appendage regeneration.

The cellular basis for appendage regeneration in MRL and $\mathrm{p} 21^{-/-}$mice also remains undefined. Lineage tracing studies in these mice have not been reported; thus, it is unknown whether appendage regeneration reflects development of an oligopotent progenitor or the collective action of multiple cell types with restricted cell fates that replace their own lineage. Organ regeneration in other animals involves activation of both mechanisms (Echeverri and Tanaka 2002; Gargioli and Slack 2004; Kragl et al. 2009; Lehoczky et al. 2011; Rinkevich et al. 2011; Tanaka and Reddien 2011; Stewart and Stankunas 2012; Sánchez Alvarado and Yamanaka 2014).

In response to tissue injury in wild-type mice, we demonstrate here that wounded keratinocytes induce Sdf1, which recruits $\mathrm{Cxcr}^{+}$leukocytes to the injured area. In p $21^{-/-}$mice, up-regulation of Sdf1 and the subsequent recruitment of Cxcr4-expressing leukocytes are significantly diminished, and appendage regeneration occurs. We show that pharmacological or conditional genetic disruption of Cxcr4 signaling and congenital leukopenia are conditions that promote tissue regeneration via lineagerestricted progenitor cells.

\section{Results}

Restriction of ectoderm and mesoderm fates in the regenerating ear

To assess the cellular origin of tissue regeneration in p $21^{-/-}$mice, we performed cell lineage tracing. We confirmed that, in response to a $2-\mathrm{mm}$ through-and-through ear puncture, the hole closed significantly better in p $21^{-1-}$ mice compared with wild-type mice (Fig. 1A,B). Hematoxylin and eosin (H\&E) staining of vertical crosssections taken from the rim of an injured wild-type ear revealed horizontally oriented fibroblasts and glassy thickened collagen, findings consistent with a sequence of wound healing, tissue fibrosis, and scar formation (Fig. 1C [for histology orientation], D,E). In contrast, the ears of $\mathrm{p} 21^{-/-}$animals consistently revealed the presence of a bulbous mass of cells surrounded by a thickened epithelium, with large, striking epidermal protrusions into the dermis (Fig. 1E) and the appearance of chondrocyte regeneration (Fig. 1D, solid vertical lines). Taken together, these morphohistological changes have been previously associated with tissue regeneration and are consistent with prior observations in MRL mice (Clark et al. 1998; Rajnoch et al. 2003; Heber-Katz et al. 2004).

We then used keratin-14-CreER (K14CreER) tamoxifeninducible transgenic mice to map the contribution of the epidermis to the regenerating ear and purify epidermal progeny for molecular analyses. K14CreER mice were crossed with mice harboring $\mathrm{mTmG}$, a double-fluorescent reporter transgene, to produce progeny (K14CreER ${ }^{\mathrm{mTmG}}$ ) in which Cre recombinase triggers genetic recombination and activation of GFP exclusively in basal keratinocytes. After tamoxifen treatment, GFP expression in wild-type K14CreER ${ }^{\mathrm{mTmG}}$ and $\mathrm{p} 21^{-/-} \mathrm{K} 14 \mathrm{CreER}{ }^{\mathrm{mTmG}}$ mice was confined to the ectodermal tissues, including dorsal and ventral epidermis, hair follicles, and secretory portions of sebaceous glands (Fig. 1F, top panels). Two-millimeter ear hole punches were performed, and histological analysis of vertical cross-sections taken from the rim of the hole demonstrated that GFP expression remained confined to ectodermal tissues after injury and was absent from mesoderm tissues, including the dermis, cartilage, and blood vessels, up to 16 wk later (Fig. 1F; Supplemental Fig. 1A). This sustained GFP expression suggests that the original tamoxifen-induced cells included epithelial stem cells, since skin keratinocytes had been replaced multiple times over the 4-mo duration of the experiment. Rarely, unlabeled columns appeared in the epidermis, likely reflecting incomplete labeling by Cre recombinase. To rule out a minor contribution from a distinct cell pool, we performed similar lineage tracing experiments with the K14Cre allele, which does not require tamoxifen for activation and marks $100 \%$ of keratinocytes with a similar ectoderm-restricted pattern (Supplemental Fig. 1B). Thus, ectoderm regeneration in $\mathrm{p} 21^{-/-}$ears originates from pre-existing ectoderm.

In addition to skin, endothelial cells and chondrocytes are two major cell types in the ear of MRL and $\mathrm{p} 21^{-/-}$ mice, and we adopted a similar conditional genetic strategy to lineage-trace and purify these mesoderm-derived descendants. To trace chondrocytes, we intercrossed collagen-2a1-CreER (Col2a1-CreER) tamoxifen-inducible transgenic mice (Nakamura et al. 2006) to create wildtype Col2a1-CreER ${ }^{\mathrm{mTmG}}$ and $\mathrm{p} 21^{-/-}$Col2a1-CreER ${ }^{\mathrm{mTmG}}$ mice. Prior to injury, GFP expression from the $\mathrm{mTmG}$ reporter was restricted to chondrocytes (Fig. 2A, top panels). After injury, vertical cross-sections taken from the rim of the ear hole in wild-type Col2a1-CreER ${ }^{\mathrm{mTmG}}$ animals demonstrated that GFP expression remained static over 1 mo, and chondrocytes did not regenerate (Fig. 2A, left panels). In $\mathrm{p}^{21^{-/-}}$Col2a1-CreER ${ }^{\mathrm{mTmG}}$ animals, we detected a new cluster of $\mathrm{GFP}^{+}$cells with the morphology and histological appearance of chondrocytes at the center of the regenerating appendage at $2 \mathrm{wk}$ and thereafter (Fig. 2A, right panels, red arrows denote new cartilage generation). These $\mathrm{GFP}^{+}$cells had increased expression of the cell proliferation marker Ki-67, supporting the view that regenerated ear cartilage arose from expansion of existing chondrocytes (Fig. 2B). In contrast, $\mathrm{GFP}^{+}$cells were not detected in other tissues, including epidermis, dermis, and blood vessels.

To assess the contribution of endothelium to the regenerating appendage, we used the Tie2Cre allele to create wild-type Tie2Cre ${ }^{\mathrm{mTmG}}$ and $\mathrm{p} 21^{-/-}$Tie2Cre ${ }^{\mathrm{mTmG}}$ mice (Koni et al. 2001). Prior to injury, GFP expression was restricted to endothelium and leukocytes, which was confirmed by immunoassaying sections for platelet endothelial cell adhesion molecule 1 (Pecam1, also called CD31) and the leukocyte marker protein tyrosine phosphatase receptor type C (Ptprc, also called CD45) (Supplemental Fig. 2). A hole punch in the ear is known to induce 
A

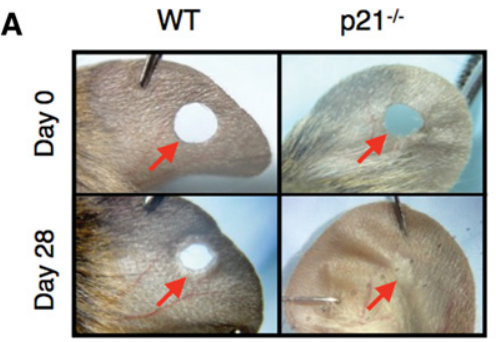

B

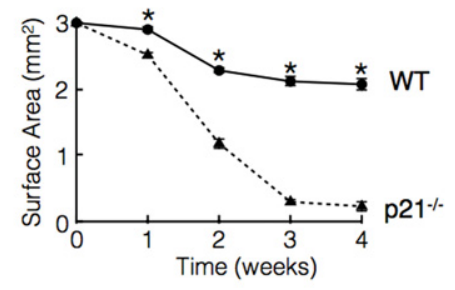

C
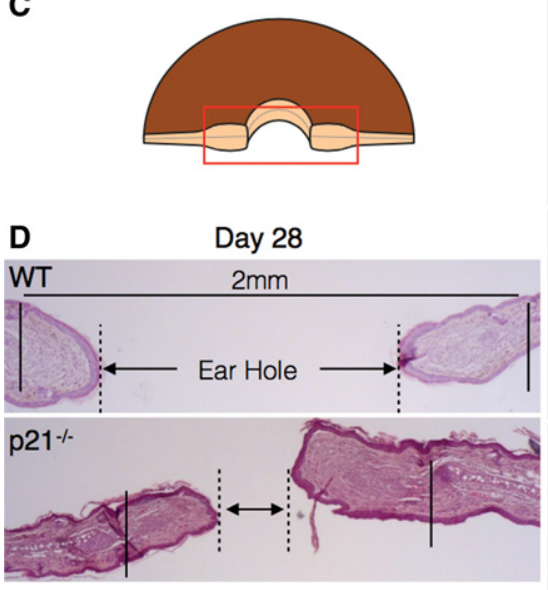

E

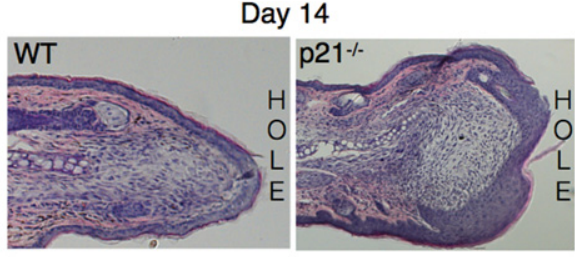

F WT K14CreERmTmG
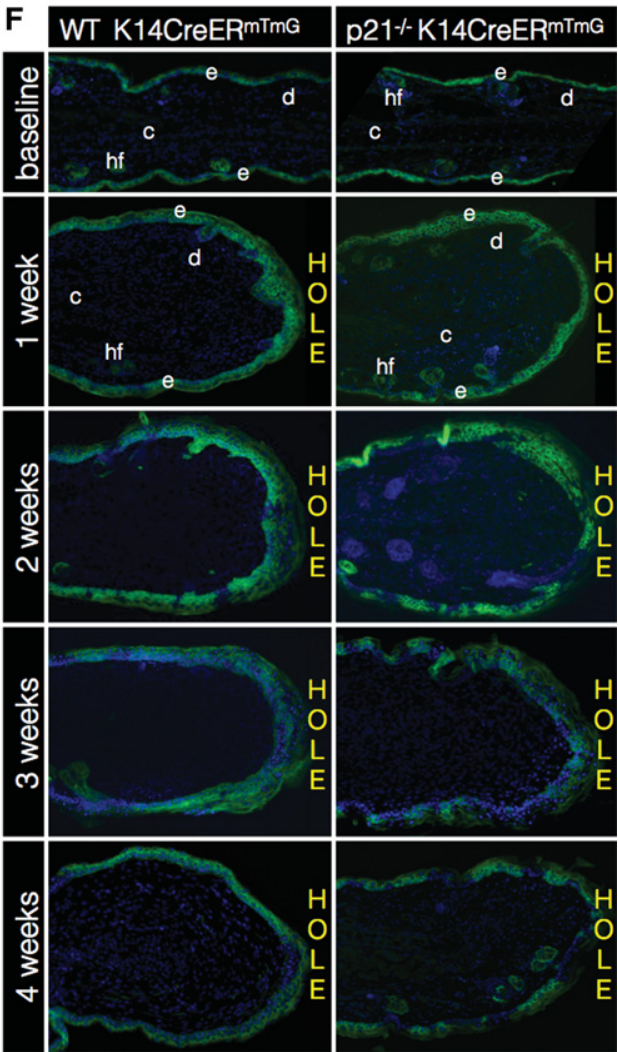

Figure 1. Restriction of ectoderm fates in the regenerating ear. $(A)$ Photographs of wounded wild-type and p2 $1^{-/-}$mouse ears on days 0 and 28. Representative images were selected from each group. $(B)$ The area of the wounded ear hole measured in wild-type and p21 ${ }^{-/-}$mice on weeks $1,2,3$, and $4 . n=12-14$ mice per group. $\left({ }^{*}\right) P<0.01$. The experiment was performed four times independently. (C) Schematic for histology orientation. The red square represents a sample histology section. $(D) \mathrm{H} \& \mathrm{E}$ staining of vertical cross-sections taken from the rim of the wound hole in wild-type and p2 $1^{-/-}$mice at day 28. Magnification, 2.5x. Solid vertical lines indicate the ends of the cartilage plate; broken lines demonstrate soft tissue borders. $(E) \mathrm{H} \& \mathrm{E}$ staining of vertical cross-sections taken from the rim of the wound hole in wild-type and $\mathrm{p} 21^{-/-}$mice at day 14. $(F)$ Vertical cross-sections of $\mathrm{K} 14 \mathrm{CreER}{ }^{\mathrm{mTmG}}$ appendages taken from the rim of the wound hole at baseline and 1-4 wk after injury for wild-type and p21 $1^{-/}$mice. GFP fluorescence (green) marks lineage-traced keratinocytes. $n=5-6$ mice per time point. For the orientation of the histology panels, the wound hole is located at the right of the section and is denoted by "hole." Unless noted, all histologic images were obtained at 10× magnification. Nuclei are blue from DAPI counterstain. (e) Epidermis; (d) dermis; (c) cartilage; (hf) hair follicle. Data are presented as average \pm SEM. Unless noted, all experiments were performed two to three times independently.

angiogenesis and recruitment of leukocytes (Park and Barbul 2004; Martin and Leibovich 2005), and, in vertical cross-sections taken from the rim of the wound, we observed an increase in $\mathrm{GFP}^{+}$cells in both wild-type Tie2$\mathrm{Cre}^{\mathrm{mTmG}}$ and $\mathrm{p} 21^{-/-}$Tie2Cre $\mathrm{e}^{\mathrm{mTmG}}$ mice (Fig. 2C; Supplemental Fig. 2). Immunohistology confirmed that nearly all $\mathrm{GFP}^{+}$cells produced either CD31 or CD45. These findings were also subsequently confirmed by cell purification using fluorescence-activated cell sorting (FACS) (see below). GFP expression was absent in other major tissue types, including epidermis and cartilage. Taken together, these lineage-tracing studies provide compelling evidence that, during ear regeneration in $\mathrm{p} 21^{-/-}$mice, keratinocytes, cartilage, and blood vessels derive from corresponding lineage-restricted progenitors.

\section{p21 $1^{-/-}$mice fail to induce Sdf1 expression in wound epithelium}

The molecular role of $\mathrm{p} 21$ in tissue regeneration remains unknown. In addition to appendage regeneration, the absence of p21 improves liver regeneration, and overexpression of p21 induces hepatic fibrosis (Willenbring et al. 2008; Weymann et al. 2009; Aravinthan et al. 2013; 


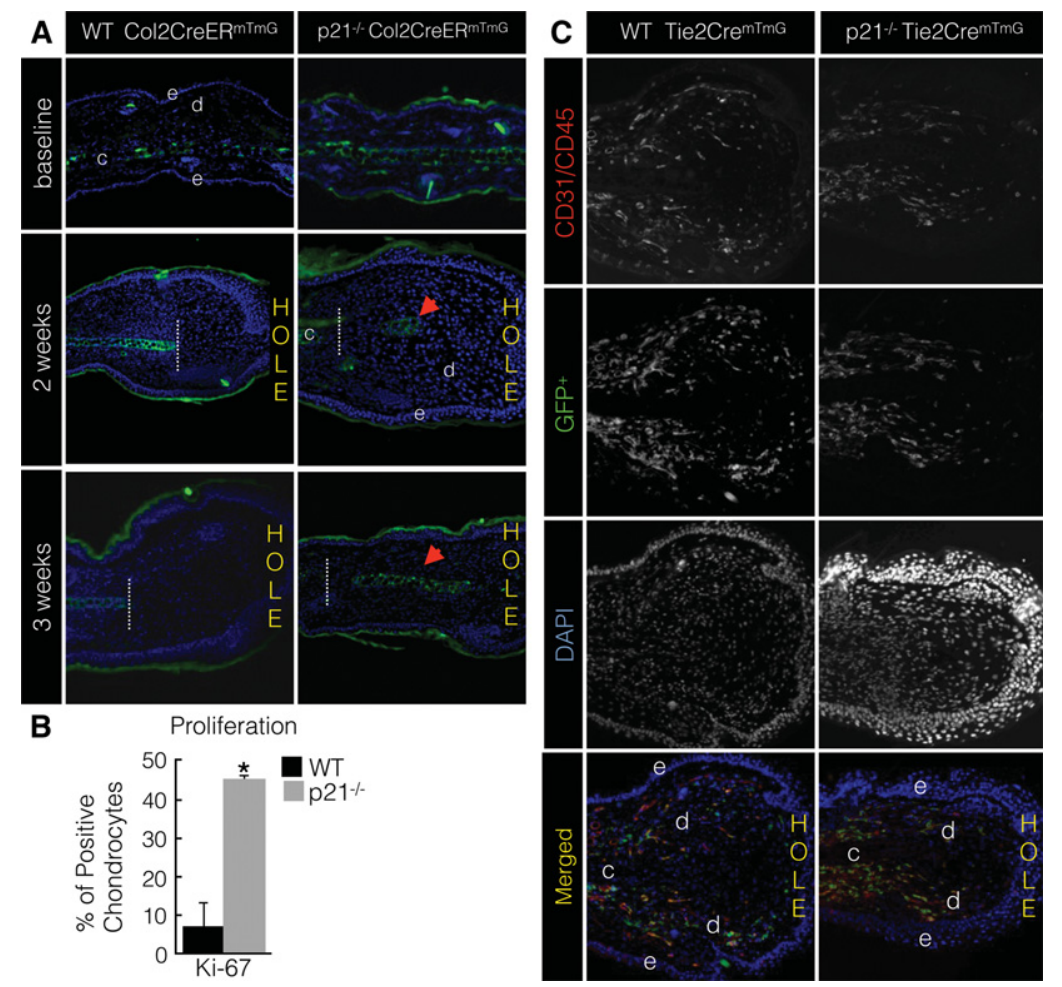

Figure 2. Restriction of mesoderm fates in the regenerating ear. $(A)$ Vertical cross-sections of Col2CreER ${ }^{\mathrm{mTmG}}$ appendages taken from the rim of the wound hole at baseline and 2-3 wk after injury for wild-type and $\mathrm{p} 21^{-/-}$mice. GFP fluorescence (green) marks lineage-traced chondrocytes. The dotted line represents the approximate plane of wounding. Red arrows denote new cartilage generation. $n=5-6$ mice per time point. $(B)$ Percentage of chondrocytes expressing Ki-67 in wild-type and $\mathrm{p} 21^{-/-}$mice at 4wk after injury. $n=4$ mice per group. $\left({ }^{*}\right) P<0.01$. $(C)$ Vertical cross-sections of Tie2Cre ${ }^{\mathrm{mTmG}}$ appendages taken from the rim of the wound hole at $2 \mathrm{wk}$ after injury for wild-type and $\mathrm{p} 21^{-/-}$mice. CD31/CD45 cells were stained with Cy5 (red), and GFP fluorescence (green) marks lineage-traced cells. $n=5-6$ mice per time point. For orientation of histology panels, the wound hole is located at the right of the section and is denoted by "hole." Magnification, 10x. Nuclei are blue from DAPI counterstain. (e) Epidermis; (d) dermis; (c) cartilage. Data are presented as average \pm SEM. All experiments were performed two to three times independently.
Buitrago-Molina et al. 2013;). In a model of chronic liver injury, the genetic deletion of Cxcr4 promoted liver regeneration (Ding et al. 2014). Thus, we postulated that Sdf1Cxcr4 signaling might be disrupted in $\mathrm{p} 21^{-/-}$animals.

After 2-mm ear hole punches were performed in wildtype and $\mathrm{p} 21^{-/-}$mice, the rim of tissue surrounding the hole was dissected and collected at regular intervals over 1 mo (Fig. 3A). After injury, a-smooth muscle actin mRNA and protein levels as well as collagen levels were significantly decreased in $\mathrm{p} 21^{-/-}$mice, indicating a regenerative response rather than accelerated fibrosis (Fig. 3B,C; Supplemental Fig. 3A). Within $3 \mathrm{~d}$ of wounding in wildtype mice, Sdf1 mRNA was also induced, but, in $\mathrm{p} 21^{-/-}$ mice, Sdf1 induction was clearly decreased (Fig. 3D).

To identify the cell types that induce Sdf1, we used GFP marking of cells in our lineage-tracing mouse colonies for FACS to purify specific cell populations for gene expression analysis. This included $\mathrm{GFP}^{+}$keratinocytes, chondrocytes, endothelial cells, and leukocytes (Supplemental Fig. 3B-E). Consistent with our other observations (Fig. 3D), quantitative RT-PCR (qRT-PCR) revealed that Sdf1 mRNA was significantly induced in wild-type keratinocytes but not $\mathrm{p} 21^{-/-}$keratinocytes (Fig. 3E). There was no significant difference in Sdf1 mRNA induction between wild-type and $\mathrm{p} 21^{-/-}$chondrocytes, endothelial cells, leukocytes, or the sorted K14CreER GFP ${ }^{\text {neg }}$ population, which includes mesenchymal cells (Fig. 3E; Supplemental Fig. 4A). We used in situ hybridization to confirm that Sdf1 mRNA was induced in wild-type keratinocytes but not $\mathrm{p} 21^{-/-}$keratinocytes (Supplemental Fig. 4B). Protein immunohistochemistry also localized the majority of Sdf1 expression to keratinocytes at the wound- ed edge, with some minor Sdf1 expression in the dermis (Fig. 3F; Supplemental Fig. 4C). In summary, we conclude that ear injury in wild-type animals induces Sdf1 expression in wound epidermis, and Sdf1 induction is dependent on $\mathrm{p} 21$.

\section{p21 regulation of Sdf1 expression}

p21 regulates gene expression in specific contexts by acting as a coactivator or corepressor (Abbas and Dutta 2009). p21 also interacts directly with the transcription factor C/ EBPa to regulate gene expression (Timchenko et al. 1997; Harris et al. 2001). In silico analysis of the human Sdf1 promoter identified an evolutionarily conserved binding site for C/EBPa, and we tested whether C/EBPa regulates Sdf1 expression (Yu et al. 2011; Mathelier et al. 2014). Cells adjacent to wounded areas are often deprived of nutrients and experience hypoxia, which are two common cell culture methods to induce Sdf1. We used shRNA to knock down $\mathrm{p} 21$ or CEBPa transcript levels in human keratinocytes (Fig. 3G, H, left panels). Consistent with our in vivo experiments, nutrient deprivation or exposure to hypoxia significantly induced Sdf1 mRNA expression in wild-type keratinocytes but not p21 knockdown cells (Fig. 3G, right panel). Similarly, nutrient deprivation or exposure to hypoxia did not induce Sdf1 significantly in C/EBPa knockdown keratinocytes (Fig. 3H, right panel). Consistent with these observations, coimmunoprecipitation studies showed that $\mathrm{p} 21$ and CEBP $\alpha$ interact directly in human keratinocytes (Supplemental Fig. 5A). Prior work has also shown that $\mathrm{p} 21$ can regulate Sdf1 expression via increased Stat3 activity during vascular wound repair 

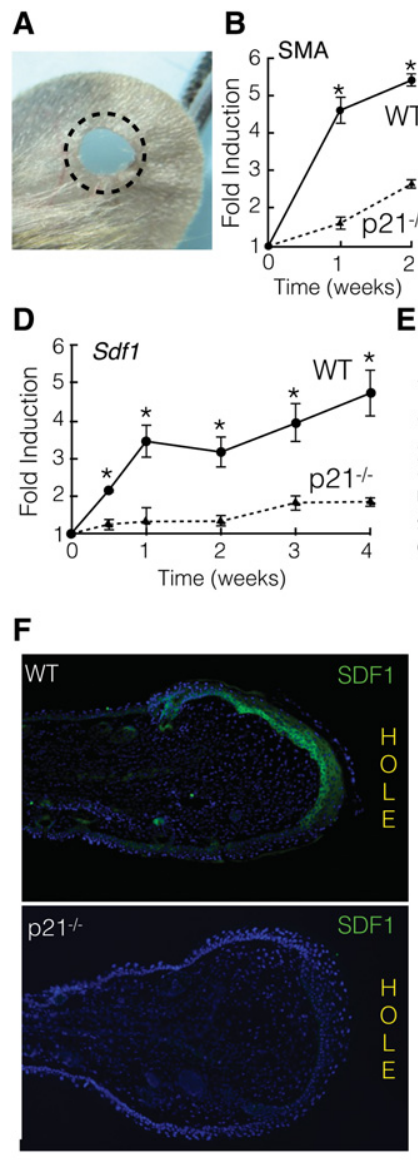

E
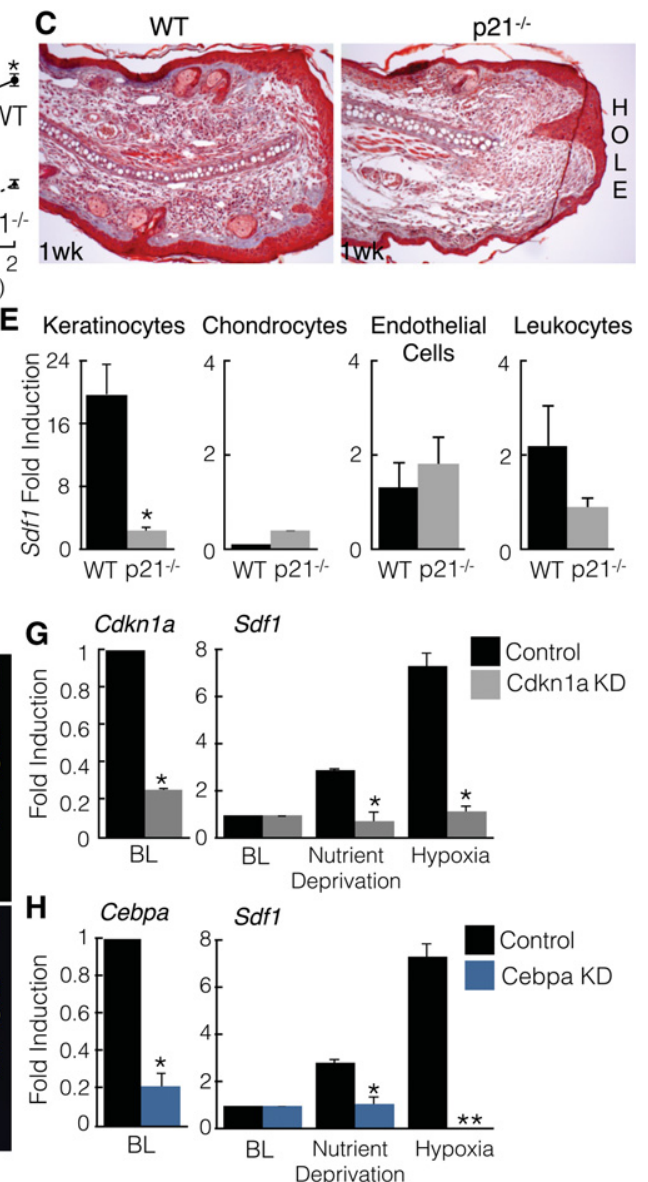

Figure 3. Lack of $S d f 1$ expression in $\mathrm{p} 21^{-/-}$wounded keratinocytes. $(A)$ Cells were isolated from the rim of a wounded ear appendage at different time points. $(B)$ Relative mRNA levels of $\alpha$-smooth muscle actin (SMA) isolated from the injury rim in wildtype and $\mathrm{p} 21^{-/}$mouse ears at baseline and weeks $1-2 . n=4-5$ mice per time point. $\left.{ }^{*}\right) P<0.05$. (C) Trichome staining on vertical cross-sections of wildtype and $\mathrm{p} 21^{-/-}$ear appendages taken from the rim of the wound hole at $1 \mathrm{wk}$ after injury. (Blue) Collagen and cartilage; (red) keratin; (black) nuclei. For orientation, the wound hole is located at the right of the section for all panels. Magnification, 10x. (D) Relative mRNA levels of $S d f 1$ in the injury rim of wild-type or $\mathrm{p} 21^{-/-}$mouse ears. $n=3-4$ mice per time point. $\left(^{*}\right) P<0.03$. (E) Relative mRNA levels of $S d f 1$ in different cell types isolated from the injury rim in wild-type and $\mathrm{p} 21^{-/-}$mice at baseline and week 1. $\left(^{*}\right) P=0.005$. $n=4-5$ mice per time point. (F) SDF1 immunostaining (green) on vertical cross-sections of wild-type and $\mathrm{p} 21^{-/}$mouse ear appendages taken from the rim of the wound hole at 1 wk after injury. For orientation, the wound hole is located at the right of the section for all panels. $(G$, left panel) Relative mRNA levels of Cdkn1a in wild-type and $C d k n 1 a$ knockdown primary human keratinocytes. (Right panel) Relative mRNA levels of $S d f 1$ in baseline, nutrient-deprived, and hypoxia-treated wild-type and $\mathrm{p} 21^{-/-} C d k n 1 a$ knockdown keratinocytes. $\left(^{*}\right) P<0.005$. (H, left panel) Relative mRNA levels of Cebpa in wild-type and Cebpa knockdown mouse embryonic fibroblasts. (*) $P<0.001$. (Right panel) Relative mRNA levels of $S d f 1$ in baseline, nutrient-deprived, and hypoxia-treated wild-type and Cebpa knockdown kerati-

nocytes. $\left({ }^{*}\right) P<0.005$; $\left(^{* *}\right)$ undetectable transcript levels and $P<0.005$. Data are presented as average \pm SEM. All experiments were performed two to three times independently.

(Olive et al. 2008), but we did not detect significant differences of Stat3 signaling in the injured ears of wild-type and $\mathrm{p} 21^{-/-}$animals (Supplemental Fig. 5B). Thus, we conclude that $\mathrm{p} 21$ interacts with $\mathrm{C} / \mathrm{EBP} \alpha$ to regulate Sdf1 gene expression.

\section{Reduced recruitment of Cxcr4 $4^{+}$leukocytes in $221^{-/-}$mice}

Cxcr4 is an established receptor for Sdf1, and, in response to injury, Sdf1 recruits $\mathrm{Cxcr} 4^{+}$cells for tissue repair (Tögel et al. 2005; Kitaori et al. 2009). In the rim of ear tissue surrounding the hole, Cxcr4 mRNA transcript and protein were up-regulated in wild-type mice, and this induction was clearly reduced in $\mathrm{p} 21^{-/-}$mice (Fig. 4A,B). Two possibilities for elevated Cxcr4 expression in the rim tissue were (1) recruitment of additional Cxcr $4^{+}$cells and (2) increased Cxcr4 expression by constituent cells.

Assessing for Cxcr4 expression in our panel of FACS-purified cell populations, we discovered that Cxcr4 mRNA was not reproducibly detected in wild-type or $\mathrm{p} 21^{-/-}$keratinocytes or chondrocytes (data not shown). In contrast, wounding induced Cxcr4 mRNA expression in $\mathrm{GFP}^{+}$cells from Tie2Cre ${ }^{\mathrm{mTmG}}$ animals in a p21-dependent fashion (Fig. 4C, left panel). Tie2Cre is expressed in leukocytes and endothelial cells. To identify the responsible cell types, we further purified the $\mathrm{GFP}^{+}$population into leukocytes $\left(\mathrm{GFP}^{+} \mathrm{CD} 45^{+}\right)$and endothelial cells $\left(\mathrm{GFP}^{+} \mathrm{CD} 45^{\text {neg }}\right)$ and discovered that Cxcr4 was not induced in either cell type (Fig. 4C, right panel). The basal level of Cxcr4 mRNA is 14-fold higher in leukocytes compared with endothelial cells (Fig. 4D), which suggests that recruitment of additional Cxcr4 ${ }^{+}$cells to the wounded ear may be responsible for the induction of Cxcr4.

Immunohistochemistry demonstrated increased recruitment of $\mathrm{CD} 45^{+}$and $\mathrm{Cxcr} 4^{+}$cells in wild-type mice to the dermal compartment compared with $\mathrm{p} 21^{-/-}$mice (Fig. 4E). Moreover, we quantified the number of cells in the wounded ear by FACS and found an approximately threefold increase of leukocytes $\left(\mathrm{GFP}^{+} \mathrm{CD} 45^{+}\right)$and, more specifically, $\mathrm{T}$ cells $\left(\mathrm{GFP}^{+} \mathrm{CD} 45^{+} \mathrm{CD}^{+}\right)$in the wounded ears of wild-type $\mathrm{Tie} 2 \mathrm{Cre}^{\mathrm{mTmG}}$ mice compared with p $21^{-/-}$Tie2Cre ${ }^{\mathrm{mTmG}}$ mice (Fig. 4F). In contrast, there was no significant difference in the number of endothelial cells at the injured rim between wild-type and $\mathrm{p} 21^{-/-}$animals. Taken together, our data indicate that the increased level of Cxcr4 mRNA in the injured ear rim reflects increased recruitment of $\mathrm{Cxcr}^{+}$leukocytes to the wounded area in wild-type mice. Consistent with these observations, we observed ear regeneration following hole punch in leukocyte-deficient nude mice that was 
A

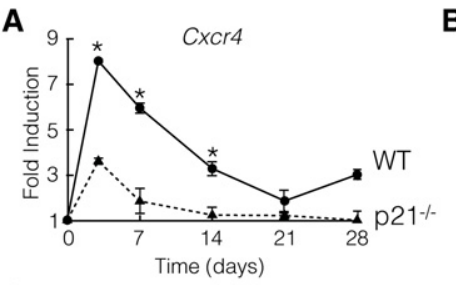

C

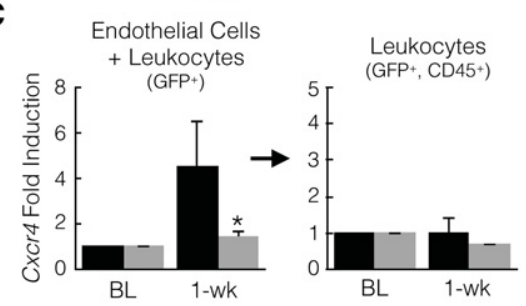

E $\quad \mathrm{CD} 45-20$
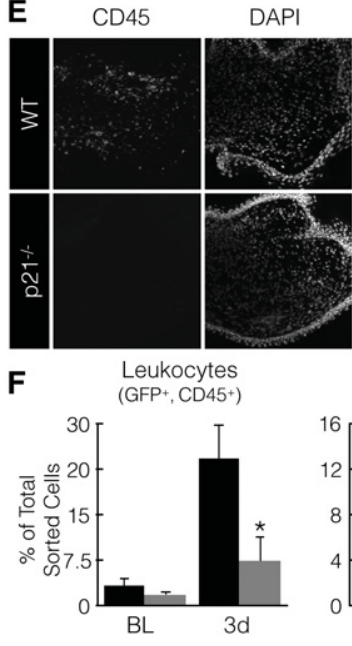

B

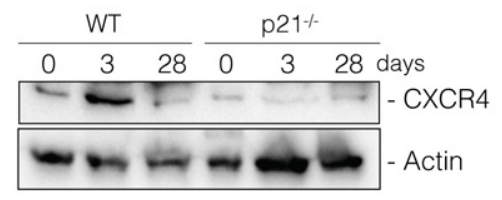

D $\mathrm{CxCr4}$

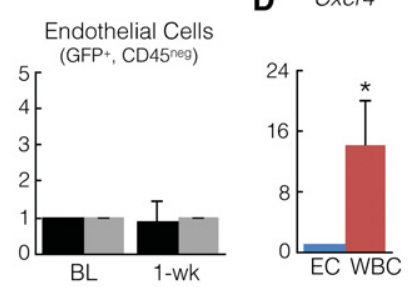

Figure 4. Failure of $\mathrm{Cxcr} 4^{+}$leukocyte recruitment to the wound rim in $\mathrm{p}^{2} 1^{-/-}$mice. $(A, B)$ Relative mRNA levels $(A)$ and protein levels $(B)$ of $C x c r 4$ in the injury rim of wild-type and $\mathrm{p} 21^{-1-}$ mouse ears at the indicated times. $n=4-5$ mice per time point. $\left(^{*}\right) P<0.01$. $(C)$ $\mathrm{GFP}^{+}$cells from Tie2Cre ${ }^{\mathrm{mTmG}}$ mice were isolated and further divided into CD45 $5^{+}$leukocyte and CD45 $5^{\text {neg }}$ endothelial cell fractions. Relative mRNA levels of Cxcr4 were compared between wild-type and $\mathrm{p} 21^{-/-}$ mice at baseline (BL) and $1 \mathrm{wk}$ after injury. $(D)$ Relative mRNA levels of Cxcr4 in endothelial cells (EC) and leukocytes (WBC). $n=6-7$ samples per group. $\left({ }^{*}\right)$ $P<0.02$. (E) CD45 and CXCR4 immunostaining on vertical cross-sections taken from the rim of the wound hole in wild-type and $\mathrm{p} 21^{-/-}$mouse appendages at 1 wk after injury. For orientation, the wound hole is located at the right of the section for all panels. $(F)$ Percentage of leukocytes, $\mathrm{T}$ cells, and endothelial cells in the total population of sorted cells from the rim of a wounded ear in wild-type and $\mathrm{p} 21^{-/-}$mice at 1 wk after injury. $n=4-8$ per treatment group. $(*) P<0.04$. Data are presented as average \pm SEM. All experiments were performed two to three times independently.

indistinguishable in appearance and tempo from that observed in $\mathrm{p} 21^{-/-}$and MRL mice (Supplemental Fig. 6), corroborating prior findings (Gawronska-Kozak 2004).

\section{Pharmacologic or genetic inhibition of Sdf1-Cxcr4 signaling promotes ear regeneration}

AMD3100 (Plerixafor) is a specific and well-characterized inhibitor of Cxcr4 in current clinical use (Hendrix et al. 2004). Based on our finding that diminished Sdf1-Cxcr4 signaling in $\mathrm{p}^{-/-}$mice promoted tissue regeneration, we hypothesized that disruption of Sdf1-Cxcr4 signaling in wild-type animals with AMD3100 might promote tissue regeneration after ear hole punch. We delivered AMD3100 or vehicle control (PBS) systemically to wildtype mice via subcutaneous osmotic pump. Compared with control animals, ear holes in AMD3100-treated wild-type mice regenerated strikingly better (Fig. 5A,B). After injury, levels of $\alpha$-smooth muscle actin mRNA and collagen expression in the ear hole tissue were also significantly decreased in AMD3100-treated mice, consistent with a regenerative response rather than accelerated fibrosis (Fig. 5C,E). As expected, induction of Sdf1 mRNA was similar in the ear hole rim tissue from both control and AMD3100-treated animals, but the amount of Cxcr4
mRNA was significantly decreased in AMD3100-treated animals and similar to the decreased Cxcr4 mRNA levels seen in $\mathrm{p} 21^{-/-}$mice (Fig. 5D). Gross and histological analysis of the injury rim in PBS control animals revealed healed epidermis without significant areas of hyperplasia, and there was no evidence of cartilage regeneration (Fig. 5E). In contrast, the rim of AMD3100-treated mice showed epidermal hyperplasia, thickened dermis, and islands of new cartilage (Fig. 5E, black arrow), changes similar to regenerating MRL and $\mathrm{p}^{-1-}$ ears (Fig. 1D). Similar to $\mathrm{p} 21^{-/-}$mice, AMD3100 treatment of wild-type mice increased the expression of Ki-67 in chondrocytes from 1\% to $30 \%$ (Fig. 5F). Finally, our data suggest that, after injury, $\mathrm{Cxcr}^{+}$cells were recruited to the injury site during the first week, and this recruitment diminished by $2-3 \mathrm{wk}$ (Fig. 4A). To test whether a shorter AMD3100 treatment interval was sufficient to restore tissue regeneration, we delivered AMD3100 (or vehicle PBS control) to wildtype mice for only $1 \mathrm{wk}$ after wounding. Compared with control animals, ear hole closure in AMD3100-treated wild-type mice was also significantly improved (Fig. 5G).

Our results with AMD3100 predicted that genetic disruption of Sdf1-Cxcr4 signaling in vivo should also promote ear regeneration. Since mice lacking Cxcr4 die in embryogenesis, we used the conditional Cxcr4 ${ }^{\mathrm{f} / \mathrm{f}}$ strain 
A
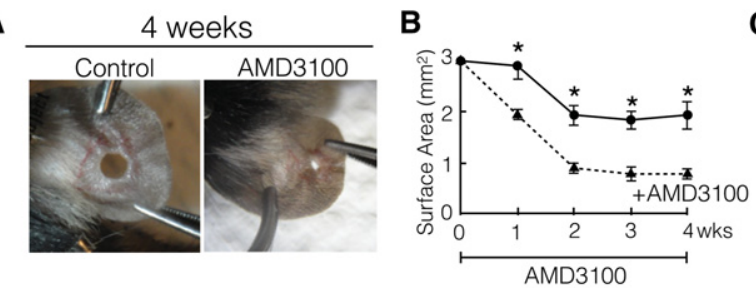

D

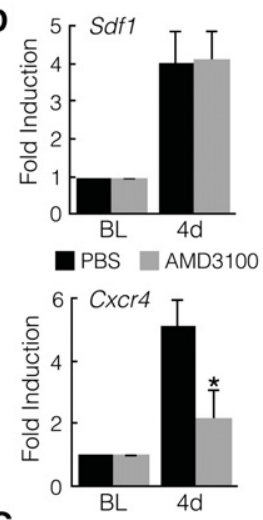

E

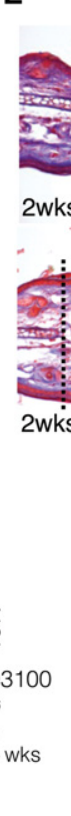

$\mathbf{F}$

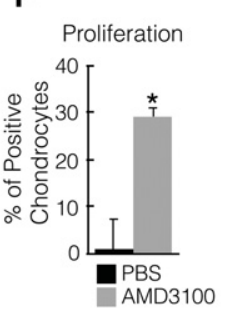

G

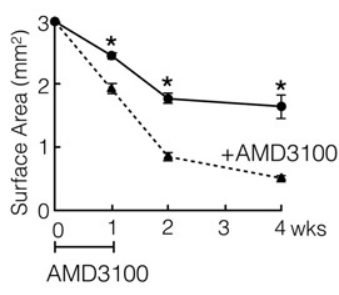

H

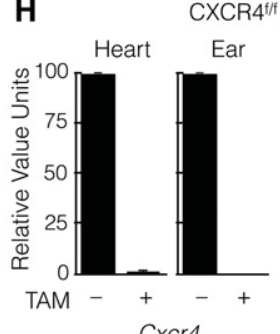

Cxcr4
PBS

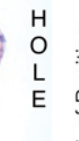

3100

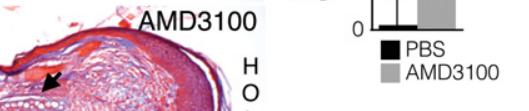

ins

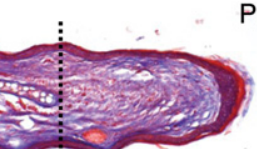

aes

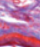

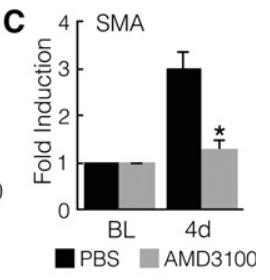

Figure 5. Genetic or pharmacologic inhibition of Sdf1-Cxcr4 signaling in wild-type mice promotes tissue regeneration. $(A)$ Photographs of control and AMD3100-treated mouse ears at week 4. (B) The area of the hole in the wounded ear at the indicated times for control and AMD3100 treatment groups. $n=8-9$ for each treatment group. $\left({ }^{*}\right) P<0.003 .(C)$ Relative mRNA levels of $a$-smooth muscle actin (SMA) at day 4 for each treatment group. $n=3-4$ for each treatment group. $\left.{ }^{*}\right) P<0.001$. $(D)$ Relative mRNA levels of $S d f 1$ and Cxcr4 at day 4 for each treatment group. $n=3-4$ for each treatment group. $\left.{ }^{*}\right) P=0.04$. $(E)$ Trichrome staining of vertical crosssections taken from the rim of the wound hole in control and AMD3100-treated appendages on day 14. (Blue) Collagen and cartilage; (red) keratin; (black) nuclei. The black arrow indicates new cartilage synthesis. The dotted line represents the approximate plane of wounding. Magnification, 10x. (F) The percentage of chondrocytes expressing Ki-67 for each treatment group. $\left({ }^{*}\right) P=0.02$. $(G)$ The area of the hole in the wounded ear at the indicated times for control and 1-wk AMD3100 pulse treatment groups. $n=8-9$ for each treatment group. $\left(^{*}\right) P<0.01$. $(H$, left panel) Relative mRNA levels of $\mathrm{Cxcr} 4$ in hearts and ears isolated from untreated and tamoxifen-treated $\mathrm{Cxcr}^{\mathrm{f} / \mathrm{f}}$ Rosa26CreER ${ }^{\mathrm{T} 2}$ mice. $n=3$ for each treatment group. (Right panel) The area of the hole in the wounded ear at the indicated times in untreated and tamoxifen-treated Cxcr4 ${ }^{\mathrm{f} / \mathrm{f}}$ Rosa26CreER ${ }^{\mathrm{T} 2}$ mice. $n=7-8$ for each treatment group. $\left({ }^{*}\right) P<0.01$. Data are presented as average \pm SEM. Representative images were selected for each group. All experiments were performed two to three times independently. to disrupt Sdf1-Cxcr4 signaling (Tachibana et al. 1998). We intercrossed Cxcr4 $4^{\mathrm{f} / \mathrm{f}}$ mice with Rosa26CreER ${ }^{\mathrm{T} 2}$ to permit efficient tamoxifen-induced conditional inactivation of Cxcr4 in all tissues except brain (Fig. 5H, left panel). Compared with untreated mice, holes in tamoxifentreated Rosa26CreER Cxcr $4^{\mathrm{f} / \mathrm{f}}$ mice regenerated better (Fig. 5H, right panel). Thus, pharmacologic or genetic disruption of Sdf1-Cxcr4 signaling induced appendage regeneration.

\section{Discussion}

The ability to regenerate lost organs following trauma is one of the great unsolved mysteries in medical research, and understanding the basis of mammalian regenerative biology is relevant to human regenerative medicine. In response to injury, wounded wild-type keratinocytes induce the expression of Sdf1, a known chemokine for Cxcr4 ${ }^{+}$ leukocytes (Fig. 6, left panel). In p21 $1^{-/-}$animals, Sdf1 induction is markedly diminished, and fewer Cxcr4 $4^{+}$leukocytes are recruited (Fig. 6, right panel). Similar to $\mathrm{p} 21^{-/-}$ animals, genetic or pharmacologic disruption of Sdf1Cxcr4 signaling promoted tissue regeneration. Regeneration of full tissue architecture without scarring argues that increased healing is not the effect of wound contraction, a distinct process that can improve wound healing but invariably results in fibrosis.
Our lineage tracing results demonstrate that lineage-restricted precursor cells for epidermis, cartilage, and endothelium, rather than oligopotent cells, work in concert to regenerate the $\mathrm{p} 21^{-/-}$appendage. Within the same species, different organs can use distinct modes of tissue regeneration. In salamanders, tails regenerate from oligopotent cells, while limbs regenerate from lineage-restricted precursor cells (Echeverri and Tanaka 2002; Kragl et al. 2009). Our lineage findings are reminiscent of studies in mammalian digit regeneration and suggest that mammalian appendages regenerate from lineage-restricted precursor cells. We cannot rule out the possibility that appendage regeneration reflects the function of an as yet undetected oligopotent cell type induced by injury. For example, it remains possible that dermal mesenchymal cells may promote regeneration, a possibility that may be tested once reliable Cre recombinase alleles for lineage-tracing these cells in vivo are available. It will also be important to continue to study other variables that may influence mammalian tissue regeneration, including the mode of injury.

The hypothesis that wound epidermis initiates or regulates tissue regeneration has been suggested in other species. In salamanders, the absence of the wound epidermis prevents limb regeneration (Thornton 1957; Carlson 2007). Deer antlers regenerate annually, but antlerogenesis is lost if the skin overlying the antler bone pedicle is 


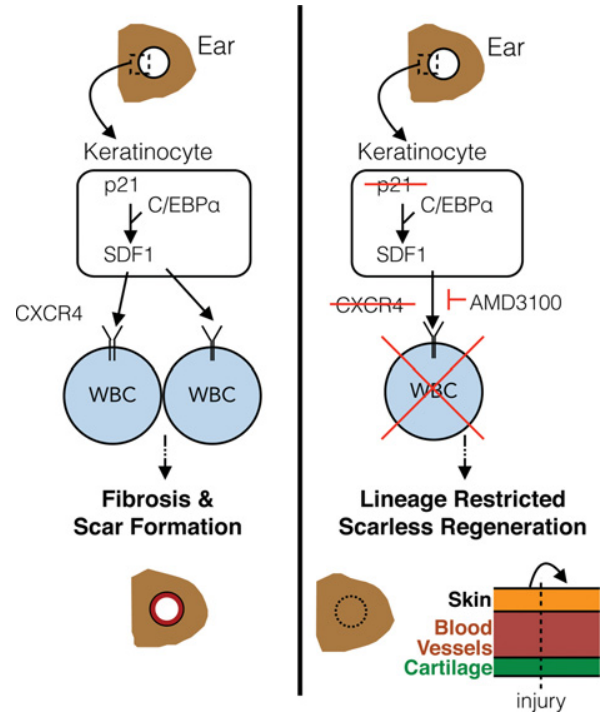

Figure 6. Chemokine signals from wound epidermis regulate tissue regeneration in mice. (Left panel) An illustration depicting how wounded wild-type keratinocytes induce Sdf1 to recruit Cxcr4 $4^{+}$leukocytes to promote fibrosis and scar formation. (Right panel) In wounded $\mathrm{p} 21^{-/}$animals, Sdf1 induction is markedly diminished, and fewer Cxcr4 $4^{+}$leukocytes are recruited, thereby permitting lineage-restricted tissue regeneration. Genetic or pharmacologic disruption of Sdf1-Cxcr4 signaling enhances tissue repair.

removed and replaced with a full-thickness skin graft (Goss 1995). These findings suggest a two-way interaction between the overlying skin and underlying skeletal tissues and cell types to coordinate tissue regeneration. Our identification of p21-dependent Sdf1 production by keratinocytes at the wounded edge is consistent with this possibility. Further localization of this effect may benefit from studies of mice with conditional p21 knockout alleles, when available. How multiple tissue-specific precursor cells expand and collaborate to restore integrated tissue architecture and function also remains to be defined.

Prior studies in digit tip regeneration have suggested that bone morphogenetic proteins like BMP2 activate Sdf1-Cxcr4 signaling in endothelial cells to promote digit tip regeneration (Lee et al. 2013). This result contrasts with our findings and other studies in the liver and lung, where the absence of Sdf1-Cxcr4 signaling promotes tissue regeneration. One possibility is Sdf1-Cxcr4 signaling in tissue regeneration may be cell type-specific or injury context-specific. BMP2 signaling is thought to primarily drive bone regeneration, and the lung, liver, and the outer ear lack bone. Consistent with this possibility, we do not see induction of BMP2 in the rim of regenerating appendages (TH Leung and SK Kim, unpubl.).

A reduced capacity to regenerate tissues has been correlated with the appearance of adaptive immunity in evolution (Mescher and Neff 2005). At sites of injury, stereotyped programs of recruitment and influx of immune cells (neutrophils, macrophages, and lymphocytes) are critical to prevent microbial infection and debride the wound (Park and Barbul 2004; Martin and Leibovich 2005). While immune cell recruitment is required to initiate early wound-healing responses, previous studies have demonstrated that some forms of immunosuppression can accelerate subsequent regeneration (Forbes and Rosenthal 2014). In humans, fetal skin regenerates after injury without scarring (unlike adult wound healing), a phenomenon accompanied by reduced immune cell infiltration and decreased inflammation (Rolfe and Grobbelaar 2012). In our studies, we found that decreased Sdf1 expression and diminished recruitment of $\mathrm{Cxcr}^{+}$leukocytes promote tissue regeneration. Our results may also explain the statistically significant linkage of the locus containing Sdf1 to regeneration in QTL studies of MRL mice (Cheverud et al. 2012). The balance between inflammatory responses and tissue regeneration is likely to be complex and multiphasic. Further studies are needed to investigate the subsets of wound $\mathrm{Cxcr} 4^{+}$leukocytes recruited by Sdf1 and understand how these cells normally promote wound healing, fibrosis, and scar formation.

We showed that Sdf1 mRNA induction requires $\mathrm{p} 21$ and $\mathrm{C} / \mathrm{EBPa}$ in keratinocytes. Consistent with this view, prior studies showed that disruption of C/EBPa enhances tissue regeneration in multiple tissues. For example, knockdown of $\mathrm{C} / \mathrm{EBPa}$ reduced injury-induced leukocyte infiltration and improved cardiac tissue regeneration (Huang et al. 2012). After partial hepatectomy, suppression of hepatic C/EBPa expression leads to an enhanced regenerative response (Greenbaum et al. 1995). Taken together, we speculate that $\mathrm{p} 21$ and $\mathrm{C} / \mathrm{EBP} \alpha$ collaborate to increase Sdf1 expression in the injured wild-type ear, which leads to recruitment of Cxcr4-expressing leukocytes and fibrosis, thereby limiting regeneration.

Using AMD3100, an established antagonist of Cxcr4 signaling, we induced appendage regeneration in wildtype animals. In the past, AMD3100, either by itself or in combination with platelet-derived growth factor or tacrolimus (Allen et al. 2014; Lin et al. 2014), improved wound healing and scar formation in diabetic mice (Nishimura et al. 2011) and mice receiving thermal burns (Avniel et al. 2005). Here we show that AMD3100 treatment promotes tissue regeneration and restores normal tissue structure and function after injury in a scarless manner. Currently, short courses of AMD3100 are used to mobilize bone marrow stem cells for transplantation in humans, and a common side effect of AMD3100 is peripheral blood leukocytosis (Hübel et al. 2004). Similar to results in mouse digit regeneration, our lineage tracing experiments suggest that hematopoietic stem cells do not contribute to ear regeneration (Lehoczky et al. 2011; Rinkevich et al. 2011). We speculate that the peripheral blood leukocytosis seen in patients may also result from disruption of Sdf1-mediated leukocyte trafficking, and future studies are needed to understand this mechanism more precisely. Collectively, our observations suggest that the clinical uses of AMD3100 may be expanded to include treatment of traumatic appendage wounds or chronic nonhealing wounds in skin. These are common problems that lack effective treatments and represent an important unmet need in current clinical practice. 


\section{Materials and methods}

Animals

Wild-type, p21 $1^{-/-}, \mathrm{Cxcr}^{\mathrm{f} / \mathrm{f}}, \mathrm{mTmG}$ reporter, K14-Cre, K14CreER, Tie-2Cre, Col2CreER, Rosa26-CreER, and J:NU mouse strains were obtained from Jackson Laboratory (strains 101045, $3263,8767,7676,4782,5107,4128,6774,8463$, and 7850, respectively). Mice were verified with genotyping instructions provided by Jackson Laboratory. For the ear wounding, we used a standard 2-mm mechanical punch to create a hole in the center of each outer ear (pinna) (Roboz). To delete reporter alleles, we administered $1 \mathrm{mg}$ of tamoxifen (diluted in corn oil) daily by intraperitoneal injection for 5-10 d, depending on the Cre line. For Cxcr4 ${ }^{\mathrm{f} / \mathrm{f}}$ mice, tamoxifen was administered for $5 \mathrm{~d}$ and then every other day for $1 \mathrm{mo}$. Mice used in this study were female age-matched littermates. All mice were housed in the animal facility of Stanford University on a 12-h light/dark cycle with ad libitum access to water and normal chow.

\section{Cell sorting}

Freshly dissected tissue from the rim of healing appendages were manually dissociated with scissors and then incubated with liberase (Roche) for $60 \mathrm{~min}$ at $37^{\circ} \mathrm{C}$. After dissociation, cells were washed in PBS and resuspended in FACS buffer (HBSS, $0.2 \%$ BSA, 1\% HEPES). 7-AAD (BioLegend) was added to exclude dead cells. FACS was performed on a FACS Aria II (BD Biosciences). Standard FACS procedures were performed; all positive sorting gates were based on negative gates, and compensation was carried out to remove spectral overlap. Sorted cells were immediately harvested for RNA purification and real-time RT-PCR analysis. The following primary antibodies were used: anti-mouse CD3 antibody (BioLegend) and anti-mouse CD45 antibody (BioLegend).

\section{Histology, in situ hybridization, and immunohistochemistry}

Standard histology and immunostaining protocols (including H\&E and Trichome) were performed. Briefly, immunohistochemical analysis was performed on 5- to $10-\mu \mathrm{m}$-thick sections of mouse skin. The following primary antibodies were used: mouse monoclonal anti-Ki-67 (1:100; Novocastra), rabbit polyclonal anti-GFP (1:200; Abcam), rabbit polyclonal anti-Sdf1 (1:100; Abcam), mouse monoclonal anti- $\alpha$ smooth muscle actin (1:100; Abcam), rabbit polyclonal anti-CD31 (1:100; Abcam), rat anti-mouse CD45 (1:100; BioLegend), and rabbit polyclonal anti-Cxcr4 (1:100; Abcam). Immune complexes were detected with secondary antibodies conjugated with either Cy3, Cy5, fluorescein isothiocyanate (Jackson ImmunoResearch), or horseradish peroxidase (Vector Laboratories). In situ hybridization on Cxcl12 was performed per the manufacturer's instructions (Advanced Cell Diagnostics); a positive control probe was directed against RNA polymerase, and a negative control probe was directed against bacterial DapB. After staining, images were directly analyzed on an AxioM1 microscope equipped with a CCD digital camera (Carl Zeiss). The number of Ki- $67^{+}$cells was counted for every $250 \mu \mathrm{m}$ of cartilage, measured at the distal tip, for each sample. A minimum of four different samples was used for each time point and then averaged.

\section{AMD3100 osmotic pump experiments}

After equilibrating an osmotic pump (Alzet, model 2004) in PBS for $36 \mathrm{~h}$, we inserted AMD3100 dissolved in PBS into the pump and implanted the pump subcutaneously into the back of the mouse. The pump released $\sim 8 \mathrm{mg}$ of AMD3100 per kilogram of body weight per day (Shu et al. 2013).

\section{Real-time RT-PCR}

Cells for RT-PCR analysis were collected in Trizol (Invitrogen). Total RNA was isolated by Direct-Zol RNA Miniprep (Zymo). RNA concentration was measured by Nanodrop 1000 (Thermo Scientific). cDNA synthesis was performed with Maxima Reverse Transcriptase (Thermo Scientific) per the manufacturer's instructions. One-step quantitative RT-PCR was performed and analyzed using an ABI Prism 7300 detection system (Applied Biosystems) with TaqMan one-step RT-PCR Master Mix reagents or SYBR Green one-step RT-PCR Master Mix reagents (Applied Biosystems). TaqMan probes were purchased for mouse genes (Acta2, Cxcr4, Cxcl12, Cdkn1a, Cebpa, $\beta$-actin, Krt10, Col2a, Pecam, and Ptprc; Life Technologies).

\section{Western blot analysis}

Total protein was prepared from mouse ear tissue by direct application of SDS sample buffer and mechanical tissue disruption. Equal amounts of protein were resolved on SDS-PAGE and transferred to nitrocellulose membranes (Bio-Rad) for immunoblotting with specific antibodies, including rabbit polyclonal anti-Cxcr4 (1:1000; Abcam), rabbit monoclonal anti-Stat3 (1:1000; Cell Signaling Technology, 4904P), rabbit monoclonal anti-PhosphoStat3 (1:1000; Cell Signaling Technology, 9145), rabbit polyclonal anti-p21 (1:1000; Santa Cruz Biotechnology), rabbit polyclonal anti-CEBPa (1:1000; Santa Cruz Biotechnology), and rabbit polyclonal anti- $\beta$-actin-HRP (1:1000; Santa Cruz Biotechnology). After further incubation with HRP-conjugated secondary antibodies, signal was visualized using ECL detection (Amersham Pharmacia) on Kodak film or Gel Doc XR ${ }^{+}$system (Bio-Rad). For the CEBPa immunoprecipitation, samples were run on a Wes (Proteinsimple) per the manufacturer's instructions with a mouse monoclonal anti-p21 antibody (Santa Cruz Biotechnology).

\section{Cell culture}

Primary human keratinocytes were obtained from the University of Pennsylvania Skin Disease Resource Center. They were grown and passaged as previously described (Leung et al. 2013). We obtained lentiviral knockdown vectors from The RNAi Consortium shRNA Library for Cdknla (TRCN287021) and CEBPa (TRCN7304). Lentivirus was produced as previously described (Leung et al. 2004). After selection, keratinocytes were seeded at 300,000 per well in six-well plates. On the following day, cells were deprived of nutrients for $24 \mathrm{~h}$ (keratinocyte media with no supplements) or exposed to $1.5 \% \mathrm{O}_{2}$ for $48 \mathrm{~h}$.

\section{Immunoprecipitation}

Briefly, hypoxia-treated keratinocytes were lysed in a nondenaturing lysis buffer $(20 \mathrm{mM}$ Tris at $\mathrm{pH} 8.0,137 \mathrm{mM} \mathrm{NaCl}, 1 \%$ Nonidet P-40, 2 mM EDTA) supplemented with protease and phosphatase inhibitors (Roche) at $4^{\circ} \mathrm{C}$. Lysates were precleared with protein $G$ beads (Invitrogen). Cell lysate $(500 \mu \mathrm{g})$ was incubated overnight with primary antibodies, including mouse monoclonal anti-p21 and rabbit polyclonal anti-CEBPa (Santa Cruz Biotechnology), and protein-G beads were added for the last $2 \mathrm{~h}$. The immunoprecipitates were washed three times with lysis buffer and eluted with SDS buffer. Western analysis was performed as described. 
Leung et al.

\section{Statistics}

A two-tailed Student's $t$-test was used to determine significance, with $P$ values of $<0.05$ considered significant. Higher levels of significance $(P<0.01$ and $P<0.001)$ are indicated in the text.

\section{Study approval}

Experiments involving mice were reviewed and approved by the Institutional Animal Care and Use Committee of Stanford University. Mice were treated in accordance with the National Institutes of Health guidelines for the humane care of animals.

\section{Acknowledgments}

We thank the Stanford Imaging Core for technical assistance; C. Spencer, J. Clark, S. Prouty, X. Yang, C. Marshall (University of Pennsylvania), and L. Zhang (Stanford University) for technical support; Dr. A. Lane (Stanford University) for helpful discussions; and Dr. T. Rando, Dr. I. Weissman, Dr. R. Baneriee, and members of the Kim laboratory for critical reading of the manuscript. T.H.L. is supported by the Dermatology Foundation and a National Institutes of Health K08 (AR066661). This work was supported by the Howard Hughes Medical Institute, Epidermolysis Bullosa Medical Research Foundation, and Epidermolysis Bullosa Research Partnership. S.K.K. is a Howard Hughes Medical Institute Investigator. T.H.L. and S.K.K. generated the hypotheses, designed the experiments, analyzed the data, and wrote the manuscript. T.H.L., E.R.S., Y.L., and J.W. performed experiments.

\section{References}

Abbas T, Dutta A. 2009. p21 in cancer: intricate networks and multiple activities. Nat Rev Cancer 9: 400-414.

Allen RJ Jr, Soares MA, Haberman ID, Szpalski C, Schachar J, Lin CD, Nguyen PD, Saadeh PB, Warren SM. 2014. Combination therapy accelerates diabetic wound closure. PLoS One 9: e92667.

Aravinthan A, Pietrosi G, Hoare M, Jupp J, Marshall A, Verrill C, Davies S, Bateman A, Sheron N, Allison M, et al. 2013. Hepatocyte expression of the senescence marker $\mathrm{p} 21$ is linked to fibrosis and an adverse liver-related outcome in alcohol-related liver disease. PLoS One 8: e72904.

Arthur LM, Demarest RM, Clark L, Gourevitch D, Bedelbaeva K, Anderson R, Snyder A, Capobianco AJ, Lieberman P, Feigenbaum L, et al. 2010. Epimorphic regeneration in mice is p53independent. Cell cycle 9: 3667-3673.

Avniel S, Arik Z, Maly A, Sagie A, Basst HB, Yahana MD, Weiss ID, Pal B, Wald O, Ad-El D, et al. 2005. Involvement of the CXCL12/CXCR4 pathway in the recovery of skin following burns. J Invest Dermatol 126: 468-476.

Bedelbaeva K, Snyder A, Gourevitch D, Clark L, Zhang X-M, Leferovich J, Cheverud JM, Lieberman P, Heber-Katz E. 2010. Lack of p21 expression links cell cycle control and appendage regeneration in mice. Proc Natl Acad Sci 107: 5845-5850.

Buitrago-Molina LE, Marhenke S, Longerich T, Sharma AD, Boukouris AE, Geffers R, Guigas B, Manns MP, Vogel A. 2013. The degree of liver injury determines the role of p21 in liver regeneration and hepatocarcinogenesis in mice. Hepatology 58: $1143-1152$.

Carlson BM. 2007. Principles of regenerative biology. Academic Press.

Chadwick RB, Bu L, Yu H, Hu Y, Wergedal JE, Mohan S, Baylink DJ. 2007. Digit tip regrowth and differential gene expression in
MRL/Mpj, DBA/2, and C57BL/6 mice. Wound Repair Regen 15: $275-284$.

Cheverud JM, Lawson HA, Funk R, Zhou J, Blankenhorn EP, Heber-Katz E. 2012. Healing quantitative trait loci in a combined cross analysis using related mouse strain crosses. Heredity (Edinb) 108: 441-446.

Choudhury AR, Ju Z, Djojosubroto MW, Schienke A, Lechel A, Schaetzlein S, Jiang H, Stepczynska A, Wang C, Buer J, et al. 2007. Cdknla deletion improves stem cell function and lifespan of mice with dysfunctional telomeres without accelerating cancer formation. Nat Genet 39: 99-105.

Clark LD, Clark RK, Heber-Katz E. 1998. A new murine model for mammalian wound repair and regeneration. Clin Immunol Immunopathol 88: 35-45.

Ding B-S, Cao Z, Lis R, Nolan DJ, Guo P, Simons M, Penfold ME, Shido K, Rabbany SY, Rafii S. 2014. Divergent angiocrine signals from vascular niche balance liver regeneration and fibrosis. Nature 505: 97-102.

Dufourcq P, Vriz S. 2006. The chemokine SDF-1 regulates blastema formation during zebrafish fin regeneration. Dev Genes Evol 216: 635-639.

Echeverri K, Tanaka EM. 2002. Ectoderm to mesoderm lineage switching during axolotl tail regeneration. Science 298: 1993-1996.

Edwards RG. 2008. From embryonic stem cells to blastema and MRL mice. Reprod Biomed Online 16: 425-461.

Forbes SJ, Rosenthal N. 2014. Preparing the ground for tissue regeneration: from mechanism to therapy. Nat Med 20: 857869.

Gargioli C, Slack JMW. 2004. Cell lineage tracing during Xenopus tail regeneration. Development 131: 2669-2679.

Gawronska-Kozak B. 2004. Regeneration in the ears of immunodeficient mice: identification and lineage analysis of mesenchymal stem cells. Tissue Eng 10: 1251-1265.

Goss RJ. 1995. Future-directions in antler research. Anat Rec 241: 291-302.

Greenbaum LE, Cressman DE, Haber BA, Taub R. 1995. Coexistence of $\mathrm{C} / \mathrm{EBP} \alpha, \beta$, growth-induced proteins and DNA synthesis in hepatocytes during liver regeneration. Implications for maintenance of the differentiated state during liver growth. J Clin Invest 96: 1351-1365.

Harris TE, Albrecht JH, Nakanishi M, Darlington GJ. 2001. CCAAT/enhancer-binding protein- cooperates with p21 to inhibit cyclin-dependent kinase-2 activity and induces growth arrest independent of DNA binding. I Biol Chem 276: 29200-29209.

Heber-Katz E, Chen P, Clark L, Zhang X-M, Troutman S, Blankenhorn EP. 2004. Regeneration in MRL mice: further genetic loci controlling the ear hole closure trait using MRL and M.m. Castaneus mice. Wound Repair Regen 12: 384-392.

Hendrix CW, Collier AC, Lederman MM, Schols D, Pollard RB, Brown S, Jackson JB, Coombs RW, Glesby MJ, Flexner CW, et al. 2004. Safety, pharmacokinetics, and antiviral activity of AMD3100, a selective CXCR4 receptor inhibitor, in HIV1 infection. J Acquir Immune Defic Syndr 37: 1253-1262.

Huang GN, Thatcher JE, McAnally J, Kong Y, Qi X, Tan W, DiMaio JM, Amatruda JF, Gerard RD, Hill JA, et al. 2012. C/ EBP transcription factors mediate epicardial activation during heart development and injury. Science 338: 1599-1603.

Hübel K, Liles WC, Broxmeyer HE, Rodger E, Wood B, Cooper S, Hangoc G, Macfarland R, Bridger GJ, Henson GW, et al. 2004. Leukocytosis and mobilization of $\mathrm{CD} 34^{+}$hematopoietic progenitor cells by AMD3100, a CXCR4 antagonist. Support Cancer Ther 1: 165-172. 
Kippin TE. 2005. p21 loss compromises the relative quiescence of forebrain stem cell proliferation leading to exhaustion of their proliferation capacity. Genes Dev 19: 756-767.

Kitaori T, Ito H, Schwarz EM, Tsutsumi R, Yoshitomi H, Oishi S, Nakano M, Fujii N, Nagasawa T, Nakamura T. 2009. Stromal cell-derived factor 1/CXCR4 signaling is critical for the recruitment of mesenchymal stem cells to the fracture site during skeletal repair in a mouse model. Arthritis Rheum 60: 813-823.

Koni PA, Joshi SK, Temann UA, Olson D, Burkly L, Flavell RA. 2001. Conditional vascular cell adhesion molecule 1 deletion in mice: impaired lymphocyte migration to bone marrow. I Exp Med 193: 741-754.

Kragl M, Knapp D, Nacu E, Khattak S, Maden M, Epperlein HH, Tanaka EM. 2009. Cells keep a memory of their tissue origin during axolotl limb regeneration. Nature 460: 60-65.

Lee J, Marrero L, Yu L, Dawson LA, Muneoka K, Han M. 2013. SDF-1a/CXCR4 signaling mediates digit tip regeneration promoted by BMP-2. Dev Biol 382: 98-109.

Lehoczky JA, Robert B, Tabin CJ. 2011. Mouse digit tip regeneration is mediated by fate-restricted progenitor cells. Proc Natl Acad Sci 108: 20609-20614.

Leung TH, Hoffmann A, Baltimore D. 2004. One nucleotide in a $\kappa \mathrm{B}$ site can determine cofactor specificity for NF- $\kappa \mathrm{B}$ dimers. Cell 118: 453-464.

Leung TH, Zhang LF, Wang J, Ning S, Knox SJ, Kim SK. 2013. Topical hypochlorite ameliorates NF-kB-mediated skin diseases in mice. J Clin Invest 123: 5361-5370.

Lin Q, Wesson RN, Maeda H, Wang Y, Cui Z, Liu JO, Cameron AM, Gao B, Montgomery RA, Williams GM, et al. 2014. Pharmacological mobilization of endogenous stem cells significantly promotes skin regeneration after full-thickness excision: the synergistic activity of AMD3100 and tacrolimus. J Invest Dermatol 134: 2458-2468.

Makino H, Aono Y, Azuma M, Kishi M, Yokota Y, Kinoshita K, Takezaki A, Kishi J, Kawano H, Ogawa H, et al. 2013. Antifibrotic effects of CXCR4 antagonist in bleomycin-induced pulmonary fibrosis in mice. J Med Invest 60: 127-137.

Martin P, Leibovich SJ. 2005. Inflammatory cells during wound repair: the good, the bad and the ugly. Trends Cell Biol 15: 599-607.

Mathelier A, Zhao X, Zhang AW, Parcy F, Worsley-Hunt R, Arenillas DJ, Buchman S, Chen C-Y, Chou A, Ienasescu H, et al. 2014. JASPAR 2014: an extensively expanded and updated open-access database of transcription factor binding profiles. Nucleic Acids Res 42: D142-D147.

Mescher AL, Neff AW. 2005. Regenerative capacity and the developing immune system. In Regenerative medicine I, Vol. 93 of advances in biochemical engineering/biotechnology, pp. 39-66. Springer, Berlin.

Nakamura E, Nguyen M-T, Mackem S. 2006. Kinetics of tamoxifen-regulated Cre activity in mice using a cartilage-specific $\mathrm{CreER}(\mathrm{T})$ to assay temporal activity windows along the proximodistal limb skeleton. Dev Dyn 235: 2603-2612.

Nishimura Y, Ii M, Qin G, Hamada H, Asai J, Takenaka H, Sekiguchi H, Renault M-A, Jujo K, Katoh N, et al. 2011. CXCR4 antagonist AMD3100 accelerates impaired wound healing in diabetic mice. J Invest Dermatol 132: 711-720.
Olive M, Mellad JA, Beltran LE, Ma M, Cimato T, Noguchi AC, San H, Childs R, Kovacic JC, Boehm M. 2008. p21Cip1 modulates arterial wound repair through the stromal cell-derived factor-1/CXCR4 axis in mice. J Clin Invest 118: 2050-2061.

Park JE, Barbul A. 2004. Understanding the role of immune regulation in wound healing. Am J Surg 187: S11-S16.

Rajnoch C, Ferguson S, Metcalfe AD, Herrick SE, Willis HS, Ferguson MWJ. 2003. Regeneration of the ear after wounding in different mouse strains is dependent on the severity of wound trauma. Dev Dyn 226: 388-397.

Rinkevich Y, Lindau P, Ueno H, Longaker MT, Weissman IL. 2011. Germ-layer and lineage-restricted stem/progenitors regenerate the mouse digit tip. Nature 476: 409-413.

Rolfe KJ, Grobbelaar AO. 2012. A review of fetal scarless healing. ISRN Dermatol 2012: 698034.

Sánchez Alvarado A, Yamanaka S. 2014. Rethinking differentiation: stem cells, regeneration, and plasticity. Cell 157: 110-119.

Shu H-KG, Yoon Y, Hong S, Xu K, Gao H, Hao C, Torres-Gonzalez E, Nayra C, Rojas M, Shim H. 2013. Inhibition of the CXCL12/CXCR4-axis as preventive therapy for radiation-induced pulmonary fibrosis. PLoS One 8: e79768.

Stewart S, Stankunas K. 2012. Limited dedifferentiation provides replacement tissue during zebrafish fin regeneration. Dev Biol 365: 339-349.

Tachibana K, Hirota S, Iizasa H, Yoshida H, Kawabata K, Kataoka Y, Kitamura Y, Matsushima K, Yoshida N, Nishikawa S, et al. 1998. The chemokine receptor CXCR4 is essential for vascularization of the gastrointestinal tract. Nature 393: 591-594.

Tanaka EM, Reddien PW. 2011. The cellular basis for animal regeneration. Dev Cell 21: 172-185.

Thornton CS. 1957. The effect of apical cap removal on limb regeneration in Amblystoma larvae. J Exp Zool 134: 357-381.

Timchenko NA, Harris TE, Wilde M, Bilyeu TA, Burgess-Beusse BL, Finegold MJ, Darlington GJ. 1997. CCAAT/enhancer binding protein $\alpha$ regulates $\mathrm{p} 21$ protein and hepatocyte proliferation in newborn mice. Mol Cell Biol 17: 7353-7361.

Tögel F, Isaac J, Hu Z, Weiss K, Westenfelder C. 2005. Renal SDF1 signals mobilization and homing of CXCR4-positive cells to the kidney after ischemic injury. Kidney Int 67: 1772-1784.

Ueno M, Lyons BL, Burzenski LM, Gott B, Shaffer DJ, Roopenian DC, Shultz LD. 2005. Accelerated wound healing of alkaliburned corneas in MRL mice is associated with a reduced inflammatory signature. Invest Ophthalmol Vis Sci 46: 40974106.

Weymann A, Hartman E, Gazit V, Wang C, Glauber M, Turmelle Y, Rudnick DA. 2009. p21 is required for dextrose-mediated inhibition of mouse liver regeneration. Hepatology 50: $207-$ 215.

Willenbring H, Sharma AD, Vogel A, Lee AY, Rothfuss A, Wang Z, Finegold M, Grompe M. 2008. Loss of p21 permits carcinogenesis from chronically damaged liver and kidney epithelial cells despite unchecked apoptosis. Cancer Cell 14: 59-67.

Yu H, Tardivo L, Tam S, Weiner E, Gebreab F, Fan C, Svrzikapa N, Hirozane-Kishikawa T, Rietman E, Yang X, et al. 2011. Nextgeneration sequencing to generate interactome datasets. Nat Methods 8: 478-480. 


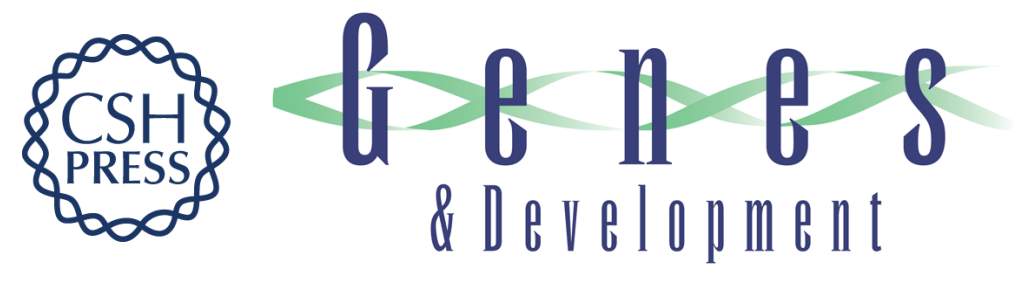

\section{A cellular, molecular, and pharmacological basis for appendage regeneration in mice}

Thomas H. Leung, Emily R. Snyder, Yinghua Liu, et al.

Genes Dev. 2015, 29:

Access the most recent version at doi:10.1101/gad.267724.115

Supplemental http://genesdev.cshlp.org/content/suppl/2015/10/22/29.20.2097.DC1
Material

References This article cites 56 articles, 10 of which can be accessed free at:

http://genesdev.cshlp.org/content/29/20/2097.full.html\#ref-list-1

Creative This article is distributed exclusively by Cold Spring Harbor Laboratory Press for the first

Commons six months after the full-issue publication date (see

License http://genesdev.cshlp.org/site/misc/terms.xhtml). After six months, it is available under a Creative Commons License (Attribution-NonCommercial 4.0 International), as described at http://creativecommons.org/licenses/by-nc/4.0/.

Email Alerting Receive free email alerts when new articles cite this article - sign up in the box at the top Service right corner of the article or click here.

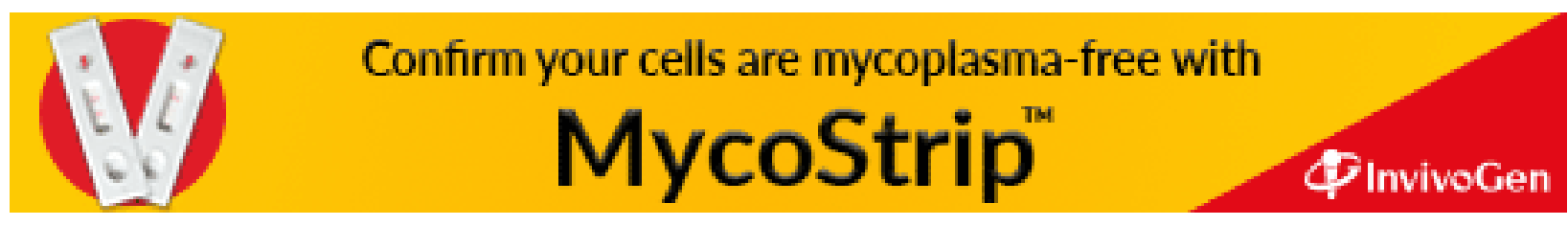

